\title{
Estimating incision healing rate for surgically implanted acoustic transmitters from recaptured fish
}

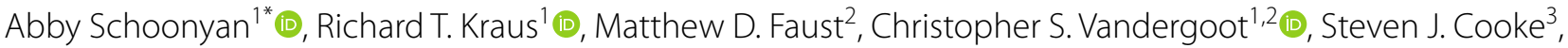 \\ H. Andrew Cook ${ }^{4}$,Todd A. Hayden ${ }^{5}$ and Charles C. Krueger ${ }^{6}$
}

\begin{abstract}
Background: Intracoelomic implantation of electronic tags has become a common method in fishery research, but rarely are fish examined by scientists after release to understand the extent that surgical incisions have healed. Walleye (Sander vitreus) are a valuable, highly exploited fishery resource in the Laurentian Great Lakes. Here, fishery capture of walleye with internal acoustic transmitters combined with a high reward program provided multiple opportunities to examine photographs and quantify the status of surgical incisions. Walleye $(n=926)$ from reef and river spawning populations in Lake Erie and Lake Huron were implanted with acoustic transmitters during spring spawning events from 2011 to 2016. Incisions were closed with polydioxanone monofilament using two to three interrupted sutures. Out of 276 recaptured fish, 60 incision sites were clearly visible in photographs, and these were scored by two independent readers for incision closure, inflammation, and the presence of sutures.
\end{abstract}

Results: While incision sites were completely closed by 61 days post-release ( $95 \% \mathrm{Cl} 44-94)$, sutures remained for up to 866 days. Sutures were expelled serially during a protracted period, and the probability of observing at least one suture in a recaptured fish declined below $50 \%$ after 673 days $(95 \% \mathrm{Cl} 442-1016)$. Inflammation at the incision increased during the first 71 days and then declined monotonically, remaining detectable at low levels.

Conclusion: Our results emphasized that sutures remained in free-ranging fish past the time when they were beneficial for incision healing. Most dissolvable sutures have been designed for use in endotherms where the body temperature and internal milieu differ dramatically from the conditions experienced by fishes in temperate climates. Identification of new suture materials for fish that facilitate healing while absorbing or dissolving in a reasonable period (e.g., a few weeks to three months) in colder temperatures (e.g., $<12^{\circ} \mathrm{C}$ ) would be beneficial to mitigate potential adverse impacts from inflammation at the incision.

Keywords: Walleye, Acoustic telemetry, Tagging effects

\section{Background}

Telemetry has become increasingly important for fishery science and management in both freshwater and marine systems [1-3]. Although numerous ways exist to affix electronic tags to fish [4], intracoelomic surgical implantation is one of the more common methods and generally regarded as being most effective for long-term

\footnotetext{
*Correspondence: aschoonyan@|ssu.edu

${ }^{1}$ Lake Erie Biological Station, Great Lakes Science Center, United States Geological Survey, 6100 Columbus Avenue, Sandusky, OH 44870, USA Full list of author information is available at the end of the article
}

tag retention provided that the incision site heals properly $[5,6]$. As with any tagging method, tagged animals are assumed to recover from the procedure and not be affected by the tag such that their behavior, health, condition, and fitness are comparable to untagged conspecifics [7]. However, that assumption is not always tested and some elements of intracoelomic implantation of electronic tags are still poorly understood. For example, the type of sutures used to close the incision wound must be considered [8]. Closure of the incision and healing after surgery can be a problem if incisions fail to properly 
close because sutures are absorbed prematurely or shed because knots are overtightened [9]. Failure of the incision to properly close can lead to transmitter loss and estimation biases related to movement and mortality [7]. In contrast, sutures that remain in the body too long can hinder the healing process and act as an attachment point for bacteria, which may lead to inflammation, infection, and various other side effects including death $[7,8,10-12]$.

Most studies evaluating surgical wounds have occurred via holding studies in a laboratory or mesocosms in the field [10-18], and a dearth of information exists for rates of healing and suture shedding from free-ranging fishes in the wild (but see $[9,19]$ ). Generally, this lack of information stems from a low probability of investigators encountering fish after release to examine surgical incisions. This limitation may be overcome when a fishery exerts substantial exploitation and an incentive (reward) can be offered to provide additional information about recaptured fish.

In our study, walleye (Sander vitreus) from two Laurentian Great Lakes (i.e., Erie and Huron) were tagged with acoustic transmitters and recaptured by commercial and recreational fisheries. A high reward (i.e., $\$ 100$ USD) was provided for the return of the tag, and participants were encouraged to provide additional information including photographs of surgical wounds. Our objective was to determine how incision healing and inflammation changed through time by using fishery-dependent, photographic data. We hypothesized that incision closure, inflammation, and suture retention would decline with days at large and evaluated whether sex of the fish affected patterns of healing. The use of fish recaptured after release into the wild yielded a novel view of the consequences of surgical transmitter implantation with implications for improving tagging methods in the future.

\section{Methods}

Recapture information (e.g., date tagged, release location, sex) compiled from several acoustic telemetry projects coordinated within the Great Lakes Acoustic Telemetry Observation System (GLATOS: http://glatos.glos.us/) was used for our analyses. Of 276 walleye recaptured from 2011 to 2016, a total of 60 fish (22\%) had pictures in which the incision site was facing the camera at significant resolution and distance for use in our analyses.

All studies used the same tagging methods, briefly described below. Walleye were collected March-April from open-water reef and tributary spawning locations in lakes Erie and Huron [20]. Fish were anaesthetized immediately prior to surgery with electroanesthesia [21]. Surgeons made an approximately $2.5-\mathrm{cm}$ mid-ventral incision, inserted an acoustic tag (model V16-4H, Vemco,
Halifax, Nova Scotia) into the body cavity, and closed the incision with two or three interrupted sutures. Ethicon PDS II (Johnson and Johnson, San Angelo, Texas) sutures were used from 2011 to 2012, whereas a comparable suture, CP Medical (CP Medical, Inc, Norcross, Georgia), was used from 2013 to 2016. According to the manufacturer specifications, both absorbable monofilament suture types were similar with respect to size, material, and absorption rate (polydioxanone [PDO], size 3/0, $24 \mathrm{~mm}$ reverse cutting needle). Surgical time was typically $<3 \mathrm{~min}$, and fish were released after a brief recovery time (approximately $15 \mathrm{~min}$ ). Depending on tagging location, five different surgeons with similar experience levels conducted the surgeries, although one surgeon performed most (i.e., $50 \%$ of recaptures) of the surgeries on fish used in this study $(n=30)$.

In addition to the acoustic transmitter, each fish received an external tag (T-bar, cinch, or anchor tag) to facilitate identification of tagged fish when harvested. A contact phone number was listed on the external tag which provided the opportunity to report the harvest of a tagged fish and receive a reward of \$100 USD. If the fish was still intact at the time of reporting, fishers were asked to provide pictures of the abdomen along with a length measurement. Fishers reported length on less than half of the 60 fish $(n=21)$, with some fish $(n=15)$ apparently shrinking or showing no growth across a wide range of days at large. Thus, we did not consider growth as an explanatory variable in our analyses. Alternatively, some tagged fish were surrendered to provincial or state natural resource agencies, which allowed more detailed measurements and photographs to be obtained.

Pictures of incision sites were scored for three metrics: surgical site inflammation, incision openness, and the presence of sutures. Fish in the pictures were typically in an oblique position and without any measurement reference (Fig. 1); therefore, we could not use digital spatial analysis of images to characterize surgical wounds. Instead, we modified scoring criteria developed by Wagner et al. [14] to quantify inflammation and incision openness (Table 1). Both inflammation and incision openness were scored from 0.0 to 1.0 by 0.05 increments. Inflammation was deemed to be present if the skin surface around the incision or suture was either pink to red in color, or raised [14]. Incision openness was scored by visually estimating the proportion of the incision that was open externally. Two readers (ALS and MDF) scored each image independently for surgical site inflammation and incision openness. Not all wounds were scored the same, and for cases where individual scores disagreed ( $n=31$ for inflammation and $n=13$ for openness), the readers developed a final consensus score. When scores differed, the average difference in scores between readers was small, 


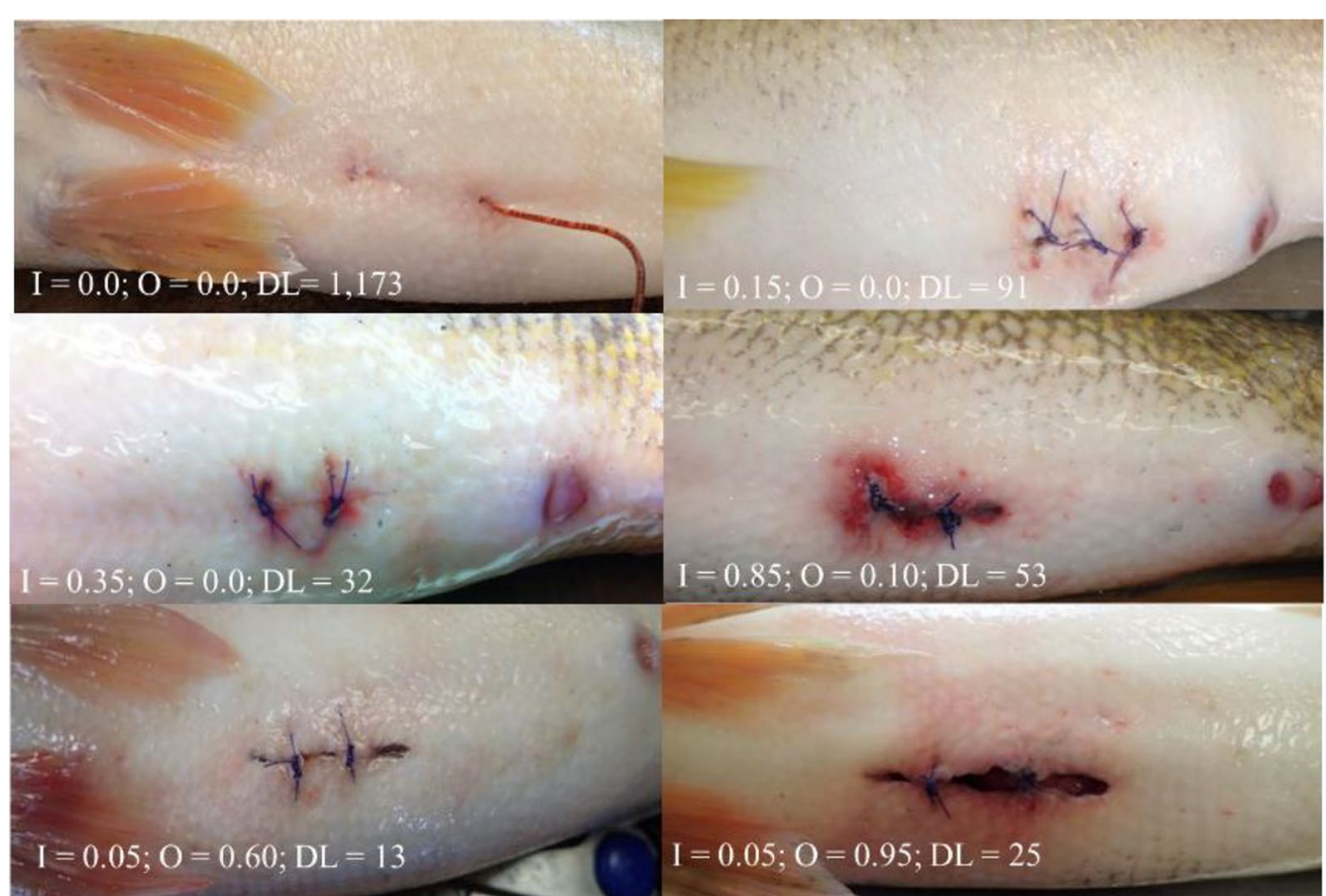

Fig. 1 Representative photographs of recaptured walleye, illustrating ranges of inflammation, wound openness, and number of sutures present at recapture. The key on each panel designates scores for inflammation (I), wound openness (O), and days at large (DL)

Table 1 Scoring criteria used to describe inflammation and incision openness of the surgical site of tagged recaptured walleye, modified from incision index of Wagner et al. [14]

\begin{tabular}{|c|c|c|}
\hline Score & Incision openness & Inflammation \\
\hline 0 & Dermis was completely healed & No inflammation present \\
\hline $0.05-0.25$ & Dermis was mostly healed (<25\% of incision open) & $\begin{array}{l}\text { Low levels of inflammation present ( }<25 \% \text { of sutures and incision } \\
\text { inflamed) }\end{array}$ \\
\hline $0.30-0.50$ & $\begin{array}{l}\text { Obvious dermal healing along less than half the length of the inci- } \\
\text { sion (between } 30 \text { and 50\% opened) }\end{array}$ & $\begin{array}{l}\text { Low to moderate levels of inflammation present (between } 30 \text { and } \\
50 \% \text { of incision and suture inflamed) }\end{array}$ \\
\hline $0.55-0.75$ & $\begin{array}{l}\text { Some obvious dermal healing along more than half }(55-75 \%) \text { of the } \\
\text { length of the incision }\end{array}$ & $\begin{array}{l}\text { Moderate to high levels of inflammation present throughout incision } \\
\text { and sutures (between } 55 \text { and } 75 \% \text { inflamed) }\end{array}$ \\
\hline $0.80-0.95$ & $\begin{array}{l}\text { Only trace evidence of dermal healing (80-90\% of the incision } \\
\text { open) }\end{array}$ & $\begin{array}{l}\text { High levels of inflammation present throughout entire incision and } \\
\text { sutures (up to 95\% of the incision and sutures inflamed) }\end{array}$ \\
\hline 1 & $\begin{array}{l}\text { No evidence of dermal healing along the length of the incision } \\
\text { (incision is 100\% open) }\end{array}$ & High levels of inflammation along incision and/or sutures \\
\hline
\end{tabular}

0.06 for inflammation and 0.02 for openness. Finally, we recorded the number of sutures present at recapture.

Separate analyses were conducted for the metrics of surgical wound status with the goal of understanding how each changed as a function of days at large. Wound inflammation has been characterized as a process beginning with rapid recruitment and localization of inflammatory cells followed by elimination of those cells via exponential decay during a protracted period [22]. We expected our results to reflect this process and fit a double-exponential model to the inflammation scores:

$$
y=\left(\frac{K_{1}}{K_{2}-\alpha}\right)\left(e^{-\alpha t}-e^{-K_{2} t}\right)
$$

where the response, $y$, was a function of time, $t$, an immediate attraction signal for recruiting inflammatory cells, $K_{1}$, and two opposing exponential rate constants, $\alpha$ and $K_{2}$ [22]. To stabilize the variance across the range of observed values and remove right skewness from the residuals, we applied a square root transformation to the inflammation score. Initial inspection of the data suggested a double-exponential pattern of rapid increase 
followed by protracted decay, but to test the importance of the initial increase in inflammation, we compared the double-exponential model with a simple exponential model, assessing the smaller Akaike's second-order information criterion, $\mathrm{AIC}_{\mathrm{c}}$, and $\Delta_{i}<2$ as support for the best model [23]. We also evaluated sex of the fish as a variable in the double-exponential model (via incorporation of a dummy variable). Due to low sample size for some surgeons, we were not able to test for surgeon effects in the double-exponential model. Instead, we conducted a separate analysis of surgeon effects on inflammation score, using ANOVA and excluding a surgeon with only one fish in our data set. The double-exponential model was fit in R (2016, The R Foundation for Statistical Computing) using the procedure outlined in Pinheiro and Bates [24] to generate starting parameter values.

Preliminary inspection of wound openness revealed a sharp decline with an abrupt transition to a state of complete wound closure. Attempts to model these data with a continuous function were unsuccessful; therefore, we estimated the transition using piecewise linear regression (i.e., broken stick or change point model; [25]). Based on the change point estimate, we subsequently evaluated effects of sex using an analysis of covariance approach for the subset of data $(n=26)$ during the rapid early decline. As with inflammation status, too few data were available to evaluate surgeon effects with respect to incision openness. With only one exception, data after the change point $(n=29)$ were invariably scored as zero; therefore, we did not attempt any analyses with this subset of data.

Finally, the number of sutures present at capture was categorized into two separate binomial variables: (1) the presence of at least one suture (i.e., sutures vs no sutures) and (2) the presence of two or more sutures. This classification was necessary because count of sutures was not recorded at the time of tagging: from two to three sutures were applied to each surgical wound. We expected a monotonic decline in each of these variables; therefore, we modeled each with logistic regression. Goodness of fit was evaluated with the Hosmer-Lemeshow test [26]. We also used a bootstrap routine [27] to develop confidence intervals for days at large when $50 \%$ of the fish had either one-or-more or two-or-more sutures.

\section{Results}

More than half of the walleye with usable images were tagged in the Detroit River $(n=19)$ and near open-water reefs $(n=17)$ of Lake Erie. The rest of the fish $(n=24)$ were tagged from tributaries in Ohio (i.e., Maumee and Sandusky rivers) and Michigan (i.e., Tittabawassee River). Of 60 walleye with usable photographs, 31 were males, 28 were females, and one was unclassified. Females were longer than males at time of tagging: $607 \mathrm{~mm}$ TL $($ s.e. $=10.1)$ compared with $560 \mathrm{~mm}$ TL (s.e. $=9.3)$, respectively ( $t$ test: $\mathrm{t}=3.4, d f=57, p=0.001$ ). Fish were recaptured after release as soon as 13 days and up to 1173 days post-tagging. Most fish (50\%) in our sample were caught within 100 days post-release. The number of sutures present at recapture varied from none $(n=11)$ to one suture $(n=13)$, two sutures $(n=33)$, or three sutures $(n=3)$. For some of the pictures we examined $(n=30$ fish), the coelom of the fish was exposed which allowed us to observe the incision internally (Fig. 2). For all of these fish (ranging in days at large from 16 to 648 days), muscle tissue on opposing sides of the incision was completely merged (i.e., no opening of the coelom to the outside could be detected), despite a lack of dermal healing externally as measured by the scoring criteria (e.g., Figure 2; Table 1). Internal photographs showed connective tissue covering the incision in some fish, and in others the incision line was barely visible, which was similar to Kaseloo et al. [18]. In the latter case, peritoneum had not yet healed over the incision. There was no evidence of inflammation internally at the incision for any of the fish, and for these fish the
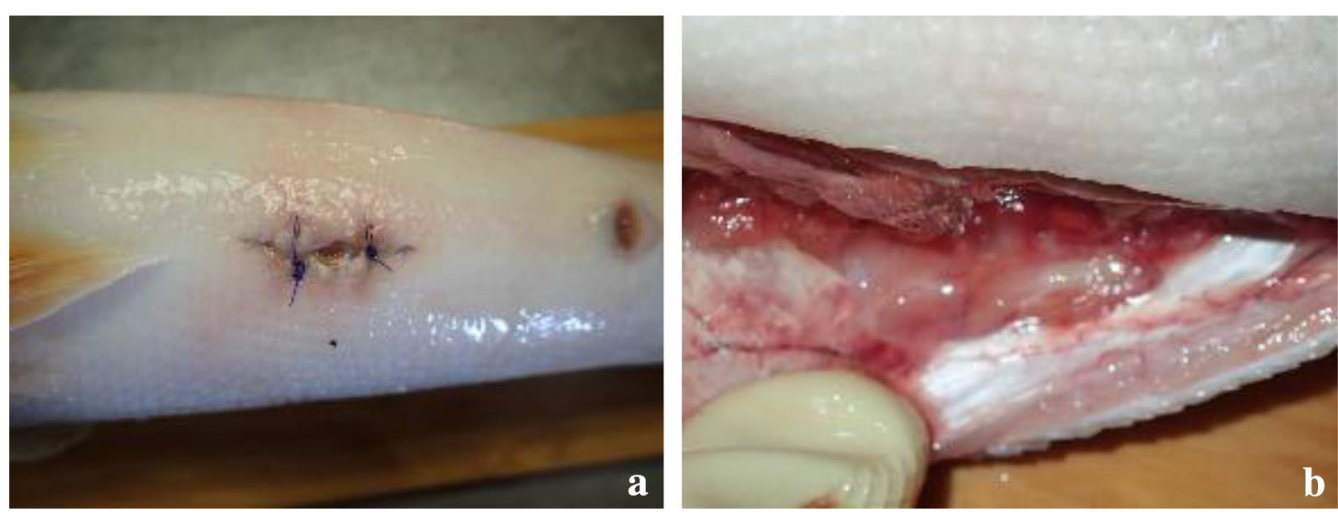

Fig. 2 Representative photograph illustrating a surgical wound that appeared open externally (a), but was closed internally (b) 
proportions of each suture category (no sutures $=0.2$, one suture $=0.2$, and two or more sutures $=0.6$ ) were similar to proportions in the overall sample.

Inflammation score declined exponentially with days at large; but, the double-exponential model provided a better fit $\left(\mathrm{AIC}_{\mathrm{c}}=-18.2\right.$, and $\left.\Delta_{i}<0.01\right)$ than the simple exponential model $\left(\mathrm{AIC}_{\mathrm{c}}=-10.4\right.$, and $\left.\Delta_{i}=7.7\right)$. A relatively short and rapid increase in inflammation occurred, peaking at approximately 92 days, followed by a slow decline, and approaching zero after two years at large (Fig. 3). The immediate attraction parameter was $K_{1}=0.0268$ (s.e. $=0.008, p<0.001$ ), and the exponential rate constants were $K_{2}=0.0387$ (s.e. $=0.015, p=0.01$ ) and $\alpha=0.003$ (s.e. $=0.0007, p=0.001$ ). The doubleexponential model had moderate explanatory power $\left(R^{2}=0.46\right)$, and none of the model parameters varied between sexes ( $p$ values $>0.4$ ). Also, inflammation scores were positively correlated with the number of sutures (Pearson's $r=0.39, d f=52, p$ value $=0.004$; Fig. 3). In the separate ANOVA of surgeon effects on inflammation, no differences were detected $(F$-statistic $=2.04, d f=49$, $p=0.12$ ).

Surgical wound openness declined rapidly, and piecewise regression identified a change point at 62 days after release ( $95 \%$ CI $46-92$ days). Wounds were completely closed after 94 days with only one exception-a fish with a slightly open wound (10\% open) at 398 days (Fig. 4).

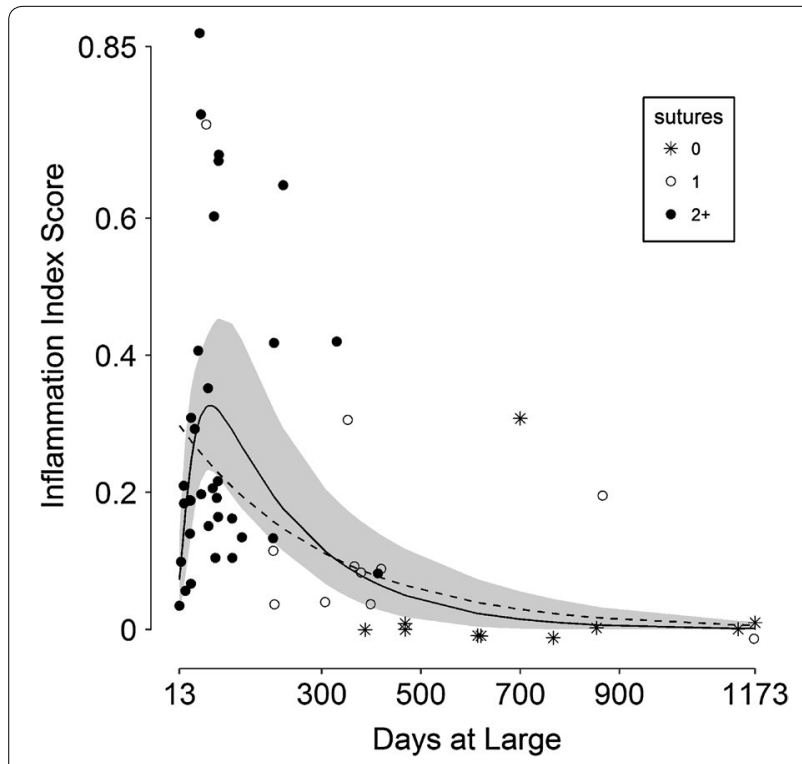

Fig. 3 Surgical wound inflammation scores for walleye $(n=60)$ as a function of days at large and the number of retained sutures (defined in the key). Shaded area delineates 95\% confidence intervals for the double-exponential model. The dashed line shows a simple exponential model for comparison. A small amount of vertical jittering has been applied to reduce symbol overlap. Each axis shows the minimum and maximum values for these data

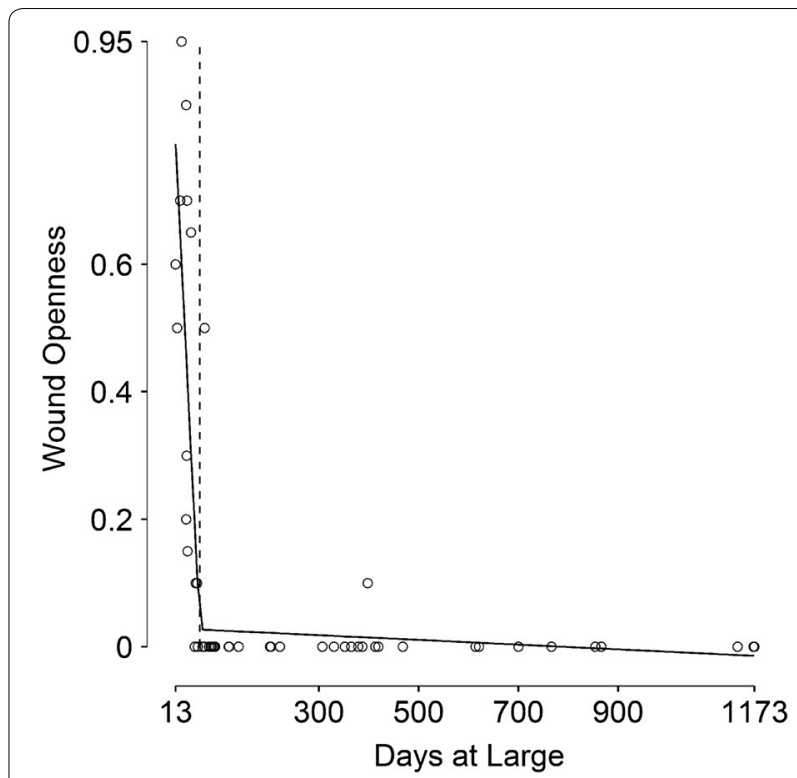

Fig. 4 Wound openness as a function of days at large for walleye from Lake Erie $(n=60)$. Piecewise regression was used to estimate the change point (vertical dashed line) at 62 days. Each axis shows the minimum and maximum values for these data

From the period prior to the change ( $<93$ days at largethe upper end of the C.I.), ANCOVA revealed no difference between sexes in either the initial estimate of wound openness (intercept) or the rate of change through time (slope). The fitted equation describing change in wound openness through time from the pooled subset of data ( $<93$ days $)$ was $y=0.79-0.009 *$ days $\left(F_{1,24}=34.1\right.$, $p<0.001, R^{2}=0.57$ ).

Sutures tended to be expelled serially rather than simultaneously. The probability of observing two or more sutures was 50\% after 259 days at large (95\% CI 178-342 days; Fig. 5). By comparison, the probability of observing at least one suture was $50 \%$ at 673 days after release (95\% CI 449-1034 days; Fig. 5). Based on 58 residual degrees of freedom, no evidence existed for lack of fit in either logistic regression model (Hosmer-Lemeshow test, $p>0.18$ ).

\section{Discussion}

The photographic information from fish recaptured after release into the wild afforded novel insights into the healing of surgical wounds of free-ranging fish. Changes in inflammation, wound openness, and suture retention were observed in fish from a natural system. The results suggested that surgical implantation of telemetry transmitters generally yielded rapid healing in the sampled population: wound openness reached 0.5 at 32 days, and most wounds were entirely closed after three months. While the surgical incision closed during a relatively 


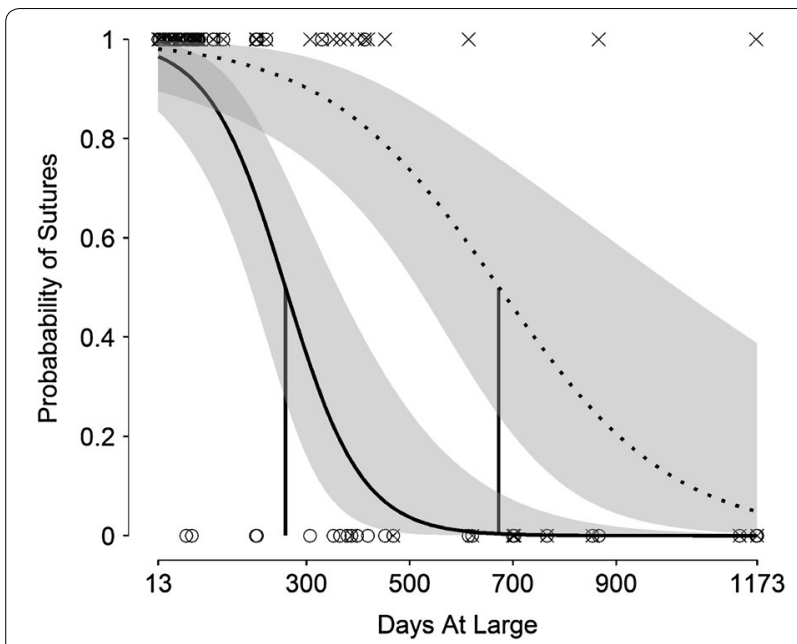

Fig. 5 Probability of suture retention as function of days at large. Shaded area delineates 95\% confidence intervals estimated with logistic regression, and the vertical lines demarcate the times at which predicted probability declined below 0.5 (determined with a bootstrap routine). Two binomial regression models are shown: (1) the presence of any sutures (" $X$ " symbols and dotted line), and (2) the presence of two or more sutures (circles and solid line)

short period, inflammation around the site was protracted for two or more years at a low level that was positively correlated with suture retention. This result indicated that PDO monofilament sutures remained in walleye past the time when needed to provide support for incision healing and may have contributed to low-level long-term irritation or infection at the incision site.

Sutures can cause skin irritation and inflammation, which is exacerbated when sutures are retained for long periods [11]. Overtightened knots and tissue bite (i.e., overlapping skin) contribute further to inflammation and can lead to infection [8]. Sutures provide necessary support to the wound during the healing process. The PDO monofilament sutures used in our study were designed to be absorbed within 180-238 days when used on endotherms. In the case of fish, sutures keep the incision closed to facilitate healing, maintain osmotic balance, and prevent infection [15]. We found that incisions in walleye were completely healed (ca. 94 days) long before sutures were expelled or absorbed (ca. 673 days), and we attributed much of this to temperature.

In fishes, suture retention increases at low temperatures and slows healing $[5,8,28]$. A trade-off exists, though, because while high temperatures promote a faster healing rate than low temperatures, a higher risk of inflammation and infection can also occur at high temperatures. Studies that used monofilament sutures similar to the sutures that we used have demonstrated wide variation in suture retention and healing in association with temperature. For example, favorable post-surgery characteristics (i.e., high tag and suture retention; low incision openness, wound inflammation, and ulceration) were observed at lower temperatures $\left(12{ }^{\circ} \mathrm{C}\right)$ in Chinook salmon (Oncorhynchus tshawytscha) when compared to higher water temperatures $\left(17^{\circ} \mathrm{C}\right.$; [10]). Similarly, healing rates and suture retention of striped bass (Morone saxatilis) were higher at lower $\left(12-18{ }^{\circ} \mathrm{C}\right)$ versus higher $\left(22-29^{\circ} \mathrm{C}\right)$ temperatures after 120 days in holding tanks [16]. In contrast, largemouth bass (Micropterus salmoides) in a pond experiment at $15.5{ }^{\circ} \mathrm{C}$ showed low suture retention, with most fish shedding all sutures and with complete incision closure by day 20 [13]. Our results were comparable to a study conducted in Warner Lake, Canada, that may be similar thermally to Lake Erie, which reported that sutures remained in largemouth bass up to 733 days post-surgery [9]. Based upon walleye tagged and released at the same time as the fish used in the present study, but outfitted with temperature loggers, our fish most likely experienced seasonal temperatures ranging on average from 2 to $21{ }^{\circ} \mathrm{C}$, with three seasons at temperatures $<12{ }^{\circ} \mathrm{C}$ [29]. We suspect that low temperatures were a likely variable in protracted suture retention for this study.

Surgical incision healing varies among species and is also affected by condition of the fish at the time of tagging and surgeon skill. Walleye in this study were tagged during the spawning period, and pre-spawn females may be particularly susceptible to side effects of the surgery because their ovaries are fragile and likely to be injured during the capture and tagging process [18]. In addition, surgeons with more experience surgically implanting tags in fish tend to finish surgery quicker with less handling, which may promote better condition in released fish than those handled by less experienced surgeons [30]. We were unable to detect any effects of surgeon or sex of the fish on incision healing in walleye.

To support inferences on the behavioral ecology of fishes, a growing body of research has been focused at evaluating swimming performance and physiological status after surgery (reviewed in Cooke et al. [5]). Our study contributed to this effort with data gathered after release and subsequent recapture via cooperation from commercial and recreational fishers. Although the effects reported here appeared to be minor, fish at large with more serious surgical complications (e.g., infection, or poor wound healing) may not have survived to be captured. Some aquatic systems are pathogen-rich or have macroscopic parasites that could gain entry through an open wound. We expect that if such cases occurred, they would primarily affect behavioral results during the early post-release period. Information on short-term post-release mortality would provide an understanding of the potential for this effect, but this has not yet been 
reported for our system and is the subject of analyses in preparation. Gross exploitation rate of tagged walleye was 30\% (276 recaptured/926 tagged), and while nonreporting rate is currently unquantified, this estimate is much higher than the exploitation rates reported in the Lake Erie walleye stock assessment for 2011-2016, which ranged from 4 to $10 \%$ [31]. Apparent higher exploitation of tagged fish when compared with population dynamics models provided evidence that walleye typically survived the tagging process well such that they could later be captured by the fishery. More work is needed to reconcile differences between population model and tagging results [32] and to determine how surgical implantation of tags affects fish on a per species basis [5].

\section{Conclusion}

Telemetry has become widely applied to fishes to better understand migration and behavior, but few studies have evaluated healing of surgical incisions in the tagged population. Our results emphasize that researchers should evaluate alternative suture materials considering the trade-off between suture retention time and healing rate to minimize potential effects of chronic inflammation on study objectives. Identification and development of new suture materials designed for ectothermic organisms (in contrast with the ones used in this study) that facilitate healing while absorbing or dissolving in a reasonable time period (e.g., a few weeks to months) would be beneficial. Improvements in the surgical methods for fish tag implantation have the potential to support more accurate inferences about migration and behavior from telemetry studies (Additional file 1).

\section{Additional file}

Additional file 1. Surgical incision scoring data from recaptured walleye that were tagged with acoustic transmitters in the Great Lakes.

\section{Authors' contributions}

ALS, RTK, MDF, CSV participated in the fieldwork, image analysis, and data analysis, and drafted the manuscript. SJC, HAC, TAH, and CCK assisted with the study design, image interpretation, and manuscript preparation. All authors read and approved final manuscript.

\footnotetext{
Author details

${ }^{1}$ Lake Erie Biological Station, Great Lakes Science Center, United States Geological Survey, 6100 Columbus Avenue, Sandusky, OH 44870, USA. ${ }^{2}$ Sandusky Fisheries Research Station, Division of Wildlife, Ohio Department of Natural Resources, 305 E. Shoreline Drive, Sandusky, OH 44875, USA. ${ }^{3}$ Fish Ecology and Conservation Physiology Laboratory, Department of Biology, Carleton University, 1125 Colonel By Drive, Ottawa, ON K1S 5B6, Canada. ${ }^{4}$ Ontario Ministry of Natural Resources and Forestry, Lake Erie Management Unit, 320 Milo Road, Wheatley, ON NOP 2P0, Canada. ${ }^{5}$ Center for Systems Integration and Sustainability, Michigan State University, Hammond Bay Biological Station, 11188 Ray Road, Millersburg, MI 49759, USA. ${ }^{6}$ Center for Systems Integration and Sustainability, Michigan State University, 115 Manly Miles Building, East Lansing, MI 48823-5243, USA.
}

\section{Acknowledgements}

We thank the Lake Erie fishers for their cooperation and enthusiasm in reporting tagged walleye. We are also grateful to Jason G. Romine for constructive reviews of this work. This work was funded by the Great Lakes Fishery Commission by way of Great Lakes Restoration Initiative appropriations (GL-00E23010). This paper is Contribution 41 of the Great Lakes Acoustic Telemetry Observation System (GLATOS). Any use of trade, product, or firm names is for descriptive purposes only and does not imply endorsement by the US Government.

\section{Competing interests}

The authors declare that they have no competing interests.

\section{Availability of data and materials}

A data file with the incision scoring is available online.

\section{Ethics approval}

All applicable international, national, and/or institutional guidelines for the care and use of animals were followed. Tagging procedures for our telemetry studies were carried out in accordance with approved animal care protocols at Carleton University (B11-10).

\section{Funding}

This work was supported with funding from the US Great Lakes Restoration Initiative, the Great Lakes Fishery Commission, and the US Geological Survey.

\section{Publisher's Note}

Springer Nature remains neutral with regard to jurisdictional claims in published maps and institutional affiliations.

Received: 17 March 2017 Accepted: 12 June 2017

Published online: 21 June 2017

\section{References}

1. Lucas MC, Baras E. Methods for studying spatial behavior of freshwater fishes in the natural environment. Fish Fish. 2000;1(4):283-316. doi:10.1046/j.1467-2979.2000.00028.x.

2. Cooke SJ, Midwood JD, Thiem JD, Klimley AP, Lucas MC, Thorstad EB, et al. Tracking animals in freshwater with electronic tags: past, present and future. Anim Biotelemetry. 2013;1:5. doi:10.1186/2050-3385-1-5.

3. Hussey NE, Kessel ST, Aarestrup K, Cooke SJ, Cowley PD, Fisk AT, et al. Aquatic animal telemetry: a panoramic window into the underwater world. Science. 2015;348(6240):1255624. doi:10.1126/science.1255642.

4. Bridger CJ, Booth RK. The effects of biotelemetry transmitter presence and attachment procedures on fish physiology and behavior. Rev Fish Sci. 2003;11(1):13-34. doi:10.1080/16226510390856510.

5. Cooke SJ, Woodley CM, Eppard MB, Brown RS, Nielsen JL. Advancing the surgical implantation of electronic tags in fish: a gap analysis and research agenda based on a review of trends in intracoelomic tagging effects studies. Rev Fish Biol Fish. 2011;21(1):127-51. doi:10.1007/ s11160-010-9193-3.

6. Thorstad EB, Rikardsen AH, Alp A, Økland F. The use of electronic tags in fish research-an overview of fish telemetry methods. Turk J Fish Aquat Sci. 2013;13:881-96. doi:10.4194/1303-2712-v13_5_13.

7. Brown RS, Eppard MB, Murchie KJ, Nielsen JL, Cooke SJ. An introduction to the practical and ethical perspectives on the need to advance and standardize the intracoelomic surgical implantation of electronic tags in fish. Rev Fish Biol Fish. 2011;21(1):1-9. doi:10.1007/ s11160-010-9183-5.

8. Wagner GN, Cooke SJ, Brown RS, Deters KA. Surgical implantation techniques for electronic tags in fish. Rev Fish Biol Fish. 2011;21(1):71-81. doi:10.1007/s11160-010-9191-5.

9. Caputo M, O'Connor CM, Hasler CT, Hanson KC, Cooke SJ. Long-term effects of surgically implanted telemetry tags on the nutritional physiology and condition of wild freshwater fish. Dis Aquat Org. 2009;84(1):3541. doi:10.3354/dao02025. 
10. Deters KA, Brown RS, Carter KM, Boyd JW, Eppard MB, Seaburg AG. Performance assessment of suture type, water temperature, and surgeon skill in juvenile Chinook salmon surgically implanted with acoustic tags. Trans Am Fish Soc. 2010;139(3):888-99. doi:10.1577/T09-043.1.

11. Panther JL, Brown RS, Gaulke GL, Woodley CM, Deters KA. Influence of incision location on tag loss, healing, incision lengths, suture retention, and growth of juvenile Chinook salmon. Pacific Northwest National Laboratory; 2010. http://jsats.pnnl.gov/Publications/Technical/2010/Panther_et_al_2010_PNNL_19192.pdf.

12. Miller EA, Froehlich HE, Cocherell DE, Thomas MJ, Cech JJ, Klimley AP, Fangue NA. Effects of acoustic tagging on juvenile green sturgeon incision healing, swimming performance, and growth. Environ Biol Fishes. 2014;97(6):647-58. doi:10.1007/s10641-013-0167-x.

13. Cooke SJ, Graeb BDS, Suski CD, Ostrand KG. Effects of suture material on incision healing, growth and survival of juvenile largemouth bass implanted with miniature radio tags: case study of a novice and experienced fish surgeon. J Fish Biol. 2003;62:1366-80. doi:10.1046/j.1095-8649.2003.00119.x.

14. Wagner GN, Stevens ED, Bryne P. Effects of suture type and patterns on surgical wound healing in rainbow trout. Trans Am Fish Soc. 2000;129(5):1196-205. doi:10.1577/1548-8659(2000)129\%3C1196:EOSTAP \%3E2.0.CO;2.

15. Knights BC, Lasee BA. Effects of implanted tags on adult bluegills at two temperatures. Trans Am Fish Soc. 1996;125(3):440-9. doi:10.1577/1548-8659(1996)125\%3C0440:EOITOA\%3E2.3.CO;2.

16. Walsh MG, Bjorgo KA, Jeffery Isely J. Effects of implantation method and temperature on mortality and loss of simulated transmitters in hybrid striped bass. Trans Am Fish Soc. 2000;129(2):539-44. doi:10.1577/1548-8659(2000)129\%3C0539:EOIMAT\%3E2.0.CO;2.

17. Deters KA, Brown RS, Boyd JW, Eppard MB, Seaburg AG. Optimal suturing technique and number of sutures for surgical implantation of acoustic transmitters in juvenile salmonids. Trans Am Fish Soc. 2012;141(1):1-10. doi:10.1080/00028487.2011.638594.

18. Kaseloo PA, Weatherley AH, Lotimer J, Farina MD. A biotelemetry system recording fish activity. J Fish Biol. 1992;40(2):165-79. doi:10.1111/j.1095-8649.1992.tb02564.x.

19. Jepsen N, Mikkelsen JS, Koed A. Effects of tag and suture type on survival and growth of brown trout with surgically implanted telemetry tags in the wild. J Fish Biol. 2008;72(3):594-602. doi:10.1111/j.1095-8649.2007.01724.x.

20. Hayden TA, Holbrook CM, Fielder DG, Vandergoot CS, Bergstedt RA, Dettmers JM, et al. Acoustic telemetry reveals large-scale migration patterns of walleye in Lake Huron. PLoS ONE. 2014;9(12):e114833. doi:10.1371/ journal.pone.0114833.
21. Vandergoot CS, Murchie KJ, Cooke SJ, Dettmers JM, Bergstedt RA, Fielder D. Evaluation of two forms of electroanesthesia and sodium bicarbonate as anesthetics for Walleye. North Am J Fish Manag. 2011;13:914-22. doi:1 0.1080/02755947.2011.629717.

22. Bardsley WG, Sattar A, Armstrong JR, Shah M, Brosnan P, Ferguson MW. Quantitative analysis of wound healing. Wound Repair Regen. 1995;3(4):426-41. doi:10.1046/j.1524-475X.1995.30407.x.

23. Burnham KP, Anderson DR. Model selection and multimodel inference: a practical information-theoretic approach, 2nd ed. New York. 2002.

24. Pinheiro JC, Bates DM. Linear mixed-effects models: basic concepts and examples. Mixed-effects models in S and S-Plus. 2000; p. 3-56.

25. Toms JD, Lesperance ML. Piecewise regression: a tool for identifying ecological thresholds. Ecology. 2003;84(8):2034-41. doi:10.1890/02-0472.

26. Hosmer DW Jr, Lemeshow S, Sturdivant RX. Applied logistic regression, vol. 398. London: Wiley; 2013.

27. Ogle DH. Introductory fisheries analyses with $R$, vol. 32. Boca Raton: $C R C$ Press; 2016.

28. Cannizzo SA, Roe SC, Harms CA, Stoskopf MK. Effect of water temperature on hydrolysis of two absorbable sutures used in fish surgery. FACETS. 2016;1:44-5. doi:10.1139/facets-2016-0006.

29. Peat TB, Hayden TA, Gutowsky LFG, Vandergoot CS, Fielder DG, Madenjian CP, Murchie KJ, Dettmers JM, Krueger CC. Seasonal thermal ecology of adult walleye (Sander vitreus) in Lake Huron and Lake Erie. J Therm Biol. 2015;53:98-106. doi:10.1016/j.jtherbio.2015.08.009.

30. Cooke SJ, Wagner GN, Brown RS, Deters KA. Training considerations for the intracoelomic implantation of electronic tags in fish with a summary of common surgical errors. Rev Fish Biol Fish. 2011;21 (1):11-24. doi:10.1007/s11160-010-9184-4.

31. Wills T, Robinson J, Faust M, Gorman AM, Belore M, Cook A, Marklevitz S, MacDougall T, Zhao Y, Hosack M. Report for 2016 by the Lake Erie Walleye Task Group. Presented to the Standing Technical Committee of the Lake Erie Committee and the Great Lakes Fishery Commission in Ypsilanti, Michigan. 2017. 26 pp. http://glfc.org/lakecom/lec/WTG_docs/annual_ reports/WTG_report_2017.pdf.

32. Vandergoot CS, Brenden TO. Spatially varying population demographics and fishery characteristics of Lake Erie Walleyes inferred from a long-term tag recovery study. Trans Am Fish Soc. 2014;143(1):188-204. doi:10.1080/ 00028487.2013 .837095

\section{Submit your next manuscript to BioMed Central and we will help you at every step:}

- We accept pre-submission inquiries

- Our selector tool helps you to find the most relevant journal

- We provide round the clock customer support

- Convenient online submission

- Thorough peer review

- Inclusion in PubMed and all major indexing services

- Maximum visibility for your research

Submit your manuscript at www.biomedcentral.com/submit
( ) BioMed Central 